\title{
Editorial - Volume 6, Number 1
}

Citation: Cannon, R. L. (2019). Editorial - Volume 6, Number 1. NeuroRegulation, 6(1), 2. http://dx.doi.org/10.15540/nr.6.1.2

Copyright: (c) 2019. Cannon. This is an Open Access article distributed under the terms of the Creative Commons Attribution License (CC-BY).
*Address correspondence to: Rex L. Cannon, PhD, BCN, Knoxville Neurofeedback Group, 7147 Kingston Pike, Ste 103, Knoxville, TN 37919, USA. Email: rcannonphd@gmail.com
Welcome to NeuroRegulation Volume 6, Issue 1. Thank you for joining us as we open the first issue of this year with a truly international offering; we are pleased to have articles from Russia, Turkey, and China, in addition to the United States. In the Research section of this issue, Olga R. Dobrushina, Zukhra Sh. Gadzhieva, Sofya N. Morozova, Elena I. Kremneva, Marina V. Krotenkova, and Larisa A. Dobrynina examine the role of the prefrontal cortex and compensatory mechanisms in mild cognitive impairment that may be a target for neuromodulation techniques. Then, Barış Gökşin, Bülent Yılmaz, and Kutay Içöz present data on the effects of neurofeedback of the alpha band on working memory performance in a normative sample of students. Finally, Lauren Kelley, Whitney Strunk, Rex Cannon, and Jeffrey Leighton present pilot data examining differences between groups of children with intrauterine drug exposure (IUDE) and attention deficit/hyperactivity disorder (ADHD). In the Perspectives section, Mark Trullinger, Allen Novian, Lori Russell-Chapin, and Deepti Pradhan present a perspective on recent publications exaggerating the effects of placebo in neurofeedback with specific focus on how non-inert shams, the false no-effect, ad hoc explanations, and confirmation bias lead to Type III statistical errors. In the Technical Notes section, Stewart P.W. Lam, Henry S.R. Kao, Xiaoyang Kao, Miranda M. Y. Fung, and Tin Tin Kao present technical and pilot data of an app that utilizes Chinese calligraphic finger-writing and Guqin music to produce changes in heart rate variability (HRV).

NeuroRegulation thanks these authors for their valuable contributions to the scientific literature for neurofeedback, neuroscience, and learning. We strive for high quality and interesting empirical topics. We encourage the members of ISNR and other biofeedback and neuroscience disciplines to consider publishing with us. It is important to stress that publication of case reports is always useful in furthering the advancement of an intervention for both clinical and normative functioning. We encourage researchers, clinicians, and students practicing neurofeedback to submit case studies, or groups of case studies!

In our sixth year, NeuroRegulation has made great strides for increasing the scientific integrity of neurofeedback, biofeedback, and applied neuroscience. We would like to thank our associate editors, reviewers, and contributors for this success. Moreover, we extend an invitation to all researchers and clinicians interested in human performance, the human brain, and methods to improve its functionality to submit reviews, theoretical articles, and research data. If we are rigorous in our efforts and clear with our data presentation, learning methods and confounds that exist in the polemic discourse between disciplines might be reduced, making way for a united, unambiguous pursuit to ensue. Our primary purpose is to aid individuals in improving functionality, no matter the obstacles one may struggle with. If we are clear in purpose, we are capable of much. I look forward to more discoveries and processes uncovered to aid in improving human performance across all functional domains.

We thank you for reading NeuroRegulation!

Rex L. Cannon, PhD, BCN

Editor-in-Chief

Email: rcannonphd@gmail.com

Published: March 25, 2019 